\title{
Fully confined Photonic band gap and Guided Modes in a Two-Dimensional Photonic Crystal Slab
}

\author{
Edmond Chow and S.Y. Lin \\ MS 0603, Sandia National Laboratories, P.O. Box 5800, Albuquerque, NM 87185 \\ Phone:505-284-3820,Fax:505-844-8985,Email:kchow@sandia.gov \\ S.G. Johnson, P.R. Villeneuve and J.D. Joannopoulos \\ Dept. of Physics, Massachusetts Institute of Technology, Cambridge, MA 02139
}

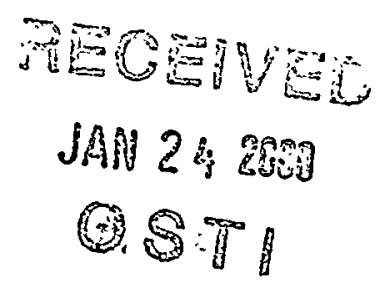

Abstract: A new two-dimensional photonic crystal (2D PC) slab structure was created with a full three-dimensional light confinement. Guided modes with broad bandwidth and high transmission within the band gap are also observed.

As an optical analog to electronic crystals, PC promises a revolution in the photonic world similar to the electronic revolution created by the electronic band gap engineering in semiconductor [1]. 2D PC has an advantage of being easier to fabricate at optical wavelength $(\lambda)$ comparing with 3D PC. However, the light leakage in the vertical direction has been the main problem for using 2D PC in opto-electronic application. In this study, we solve this problem by combining traditional 2D PC with strong vertical index guiding between the waveguide layer (GaAs) and the cladding layer $\left(\mathrm{Al}_{\mathrm{x}} \mathrm{O}_{\mathrm{y}}\right)$.

A set of triangular lattice holes $2 \mathrm{D}$ PC's were fabricated with lattice constant $a=460 \mathrm{~nm}$, hole diameter $(d=0.6 \mathrm{a})$ and waveguide layer thickness $(t=0.5 \mathrm{a})$. Those parameters were chosen to maximize [2] the TE photonic band gap (PBG) around $\lambda=1.55 \mu \mathrm{m}$. Fig. 1 shows the SEM top view of a nine periods PC. The depth of etched holes is $\sim 0.6 \mu \mathrm{m}$ and the $2 \mu \mathrm{m}$ thick $\mathrm{Al}_{\mathrm{x}} \mathrm{O}_{\mathrm{y}}$ cladding layer is obtained by thermal oxidation of $\mathrm{Al}_{0.9} \mathrm{Ga}_{0.1} \mathrm{As}$. PC waveguides were also created by introducing line defects along $\Gamma \mathrm{K}$ direction.

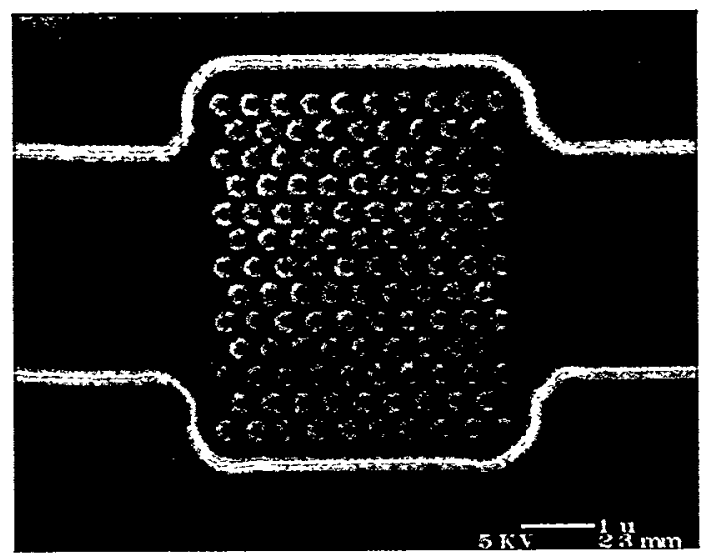

Fig. 1(a) shows the SEM top view of a nine periods PC.

We perform transmission measurement by coupling light to $\mathrm{PC}$ with $3 \mu \mathrm{m}$ wide waveguides which extends $\sim 0.6 \mathrm{~mm}$ on both sides of PC. An aspheric lens with NA=0.4 is used to focus the collimated light from tunable diode laser into the input waveguide. Another identical lens is used to collect the transmitted light and focus to an infrared (IR) camera and a calibrated photo-detector with a beamsplitter. Fig. 2 shows images from IR camera at output waveguide of a nine periods PC with $1.55 \mu \mathrm{m}$ TE (left) and TM (right) input light. The Gaussian waveguide mode shown in Fig. 2 indicates that the signal detected by the photodetector comes only from the light interacting with PC and propagating along the waveguide. The absolute transmittance is obtained by normalizing the transmission with a reference measured with a nominally identical waveguide without PC. 


\section{DISCLAIMER}

This report was prepared as an account of work sponsored by an agency of the United States Government. Neither the United States Government nor any agency thereof, nor any of their employees, make any warranty, express or implied, or assumes any legal liability or responsibility for the accuracy, completeness, or usefulness of any information, apparatus, product, or process disclosed, or represents that its use would not infringe privately owned rights. Reference herein to any specific commercial product, process, or service by trade name, trademark, manufacturer, or otherwise does not necessarily constitute or imply its endorsement, recommendation, or favoring by the United States Government or any agency thereof. The views and opinions of authors expressed herein do not necessarily state or reflect those of the United States Government or any agency thereof. 


\section{DISCLAIMER}

Portions of this document may be illegible in electronic image products. Images are produced from the best available original document. 


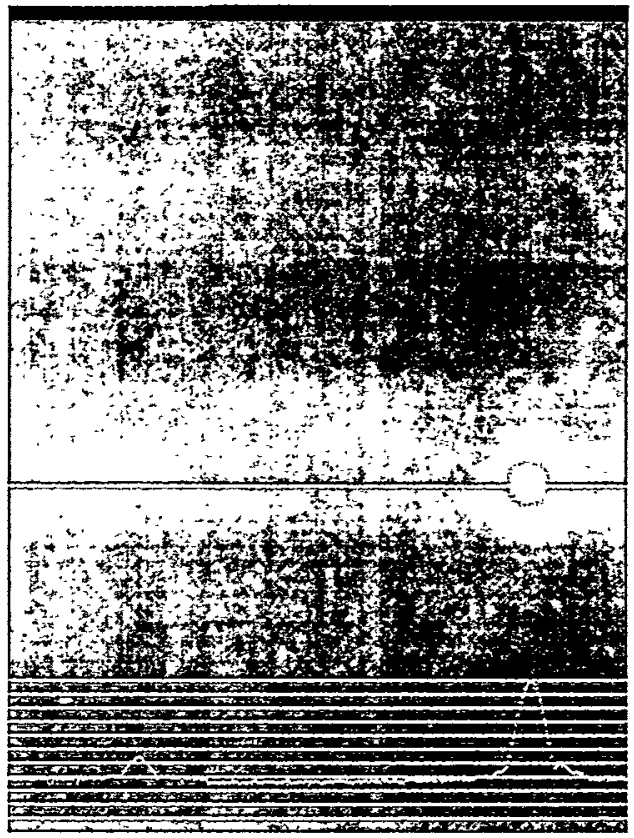

Fig.2 shows the images from IR camera taken at the output waveguide of a nine periods PC with $1.55 \mu \mathrm{m} \mathrm{TE}$ (left) and TM(right) input light.

In Fig. 3, we plot the transmittance versus $\lambda$ measured on PC and PC waveguide. The circle and square symbols represent the TE and TM transmittance of a nine periods PC. From $\lambda=1.525-1.68 \mu \mathrm{m}$, we see a wide TE PBG with transmittance $\sim 0.1 \%$ while the TM transmittance remains $\sim 70 \%$. Sharp band edges for TE and TM bands are observed around $\lambda=1.32 \mu \mathrm{m}$ which agrees with band structure calculation [2] within $10 \%$. The triangle symbols represent the TE transmittance of a sixteen periods of PC waveguides and the curve is a guide of sight. It shows a PC waveguide band with peak transmittance $\sim 50 \%$ at $\sim 1.65 \mu \mathrm{m}$. To the best of our knowledge, this is the first demonstration of waveguiding in the optical $\lambda$ regime in any 2D PC structure. Using a narrower input waveguide is expected to give a much higher transmittance and the line defects can also be used to create compact waveguide bend [3], both of these approaches are currently under progress. 


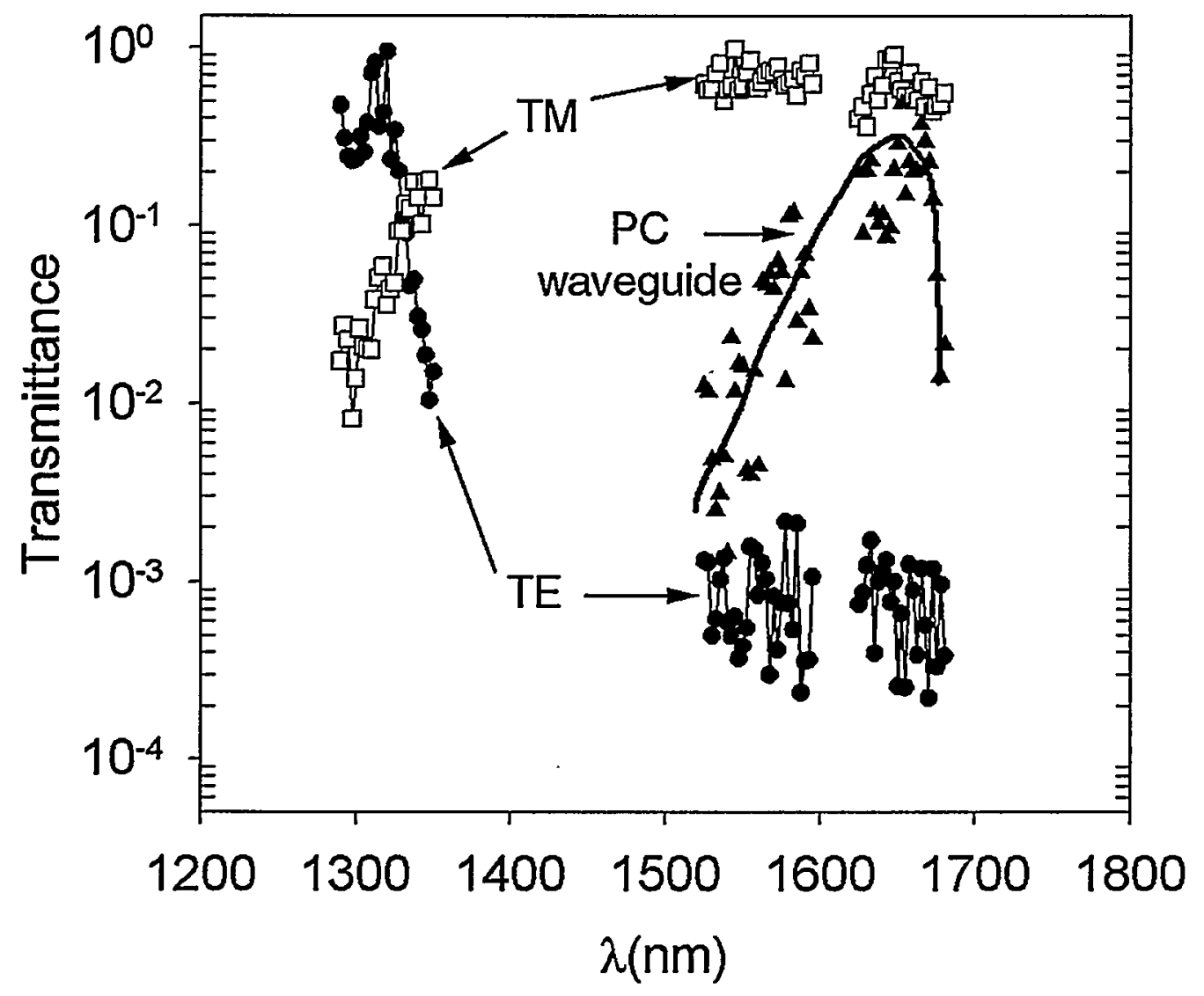

Fig. 3 shows transmittance versus $\lambda$. The circle and square symbols represent TE and TM transmittance of a nine periods regular PC. The triangle symbols represent TE transmittance of a sixteen periods PC waveguide and the curve is a guide of sight.

1. J.D. Joannopoulos, P.R. Villeneuve, S. Fan, Nature, 386, 143-149 (1997).

2. S.G. Johnson, S.Fan, P.R. Villeneuve, J.D. Joannopoulos, Phys. Rev. B $605751-5758$ (1999).

3. S.Y. Lin, E. Chow, V. Hietala, P.R. Villeneuve, J.D. Joannopoulos, Scierice, 282 274-276 (1998)

Sandia is a multiprogram laboratory operated by Sandia Corporation, a Lockheed Martin Company, for the United States Department of Energy under contract DE-AC04-94AL85000. 